\title{
The swirl ratio influence on combustion process and heat transfer in the opposed piston compression-ignition engine
}

In order to maximise engine heat efficiency an engines charge flow must be properly designed-especially its swirl and tumble ratio. A two-stroke compression-ignition opposed piston engine reacts to engine swirl differently compared to a standard automotive engine with axially symmetric combustion chamber. In order to facilitate direct fuel injection, high-pressure injectors must be positioned from the side of combustion chamber. Depending on the combustion chamber geometry the swirling gases impact greatly how the injection stream is formed. If the deformation is too high the high temperature combustion gases can hit the piston surface or get into gaps between the pistons. This greatly affects the heat lost to the pistons and raises their local temperature. More atomised injection stream is more prone to swirling gas flow due to its reduced droplet size and momentum. The paper presents simulation results and analyses for different intake process induced swirl ratios and different types of combustion chambers in an experimental aviation opposed piston engine.

Key words: opposed, two-stroke, combustion, heat, diesel

\section{Introduction}

The compression ignition engines are more thermodynamically efficient than the SI engines, even though the theoretical thermodynamic cycle seems less efficient at first glance (heat capacity is higher for the constant pressure heat addition). Higher efficiency is achieved because of the lean combustion and higher compression ratio - not feasible in SI engines due to knock combustion phenomena. Lean combustion in an CI engine ensures better isolation of hot combustion gases from cold combustion chamber walls. This is the reason why proper injection, intake, exhaust and combustion process design is important for the heat loses. Additionally, some energy can be recuperated with turbocompressor. In order to isolate hot combustion gases from chamber walls an indentation in the piston is introduced. During the injection, nearly all gas mixture is enclosed by that indentation. Additionally, squeezing all gas into small confined volume creates a "squish" phenomena which amplifies swirling motion and turbulence properties. The smaller the combustion chamber active area the smaller the heat flux will be. This is why it is favourable to make more spherical combustion chamber as sphere has the best volume to surface ratio

The swirling motion of the gas is defined by axial swirl and radial swirl called "tumble". In order to estimate the swirl ratio, an axis of rotation have to be known. The swirl ratio can be calculated with formula:

$$
\mathrm{R}_{\mathrm{S}}=\frac{60}{2 \pi \mathrm{n}} \frac{-\sum_{i} m_{i}\left[\left(\mathrm{x}_{\mathrm{i}}-\mathrm{x}_{\mathrm{C}}\right) v_{\mathrm{i}}-\left(\mathrm{y}_{\mathrm{i}}-\mathrm{y}_{\mathrm{C}}\right) \mathrm{u}_{\mathrm{i}}\right]}{\sum_{i} m_{i}\left[\left(\mathrm{x}_{\mathrm{i}}-\mathrm{x}_{\mathrm{C}}\right)^{2}-\left(\mathrm{y}_{\mathrm{i}}-\mathrm{y}_{\mathrm{C}}\right)^{2}\right]}
$$

where $\mathrm{C}=\left(\mathrm{x}_{\mathrm{c}}, \mathrm{y}_{\mathrm{c}}, \mathrm{z}_{\mathrm{c}}\right)$ represents the center of mass of the whole combustion chamber gas region [1].

\section{Materials and Methods}

The paper presents the simulation results of thermodynamic CFD hypothetical two stroke compression ignitions opposed engine simulations, that is being designed for use in light aircraft. High power to weight ratio and thermal efficiency are the key values of the engine. Designing a new engine is bound to many uncertainties and variables. In order to investigate engine working cycle phenomena, the simulation is split into combustion and intake/exhaust parts (Fig. 1).

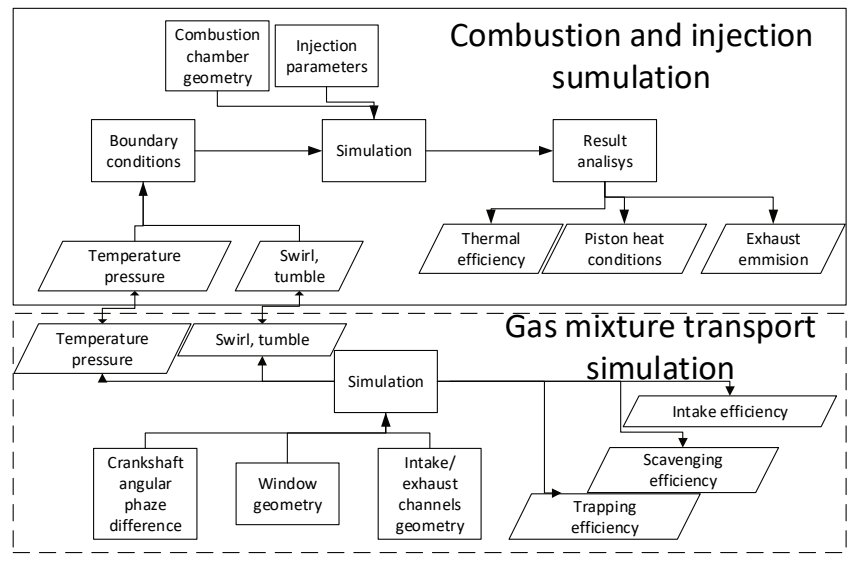

Fig. 1. Information flow diagram for engine work cycle optimization simulations

The gas transport simulation is intended to find optimal intake and exhaust windows geometry for a required mass that needs to be transported into combustion chamber, required swirl, tumble and minimal energy loses. In order to find out what swirl ratio will be best for a given load a combustion simulation is conducted with variable swirl ratio as an initial condition. The combustion simulation therefore stars after intake windows close and finishes before the exhaust windows open. It allows for combustion chamber geometry and injection parameters optimization, maximising engine heat efficiency and minimizing heat flux through chamber walls. This paper presents mainly the impact of varying swirl ratio on combustion process. The simulations were performed in the AVL Fire software. Throughout the optimization process many combustion chamber geometries were developed. Some of them are presented in Fig. 2. Geometry v4 is the simplest one with 
symmetry in all perpendicular planes. Geometries v4, v7 and v8 are further improvements, with increased sphericity of piston bowl and with flow disturbing edges deformations.

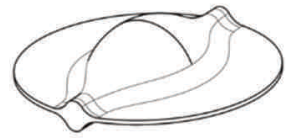

v4

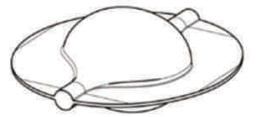

v7

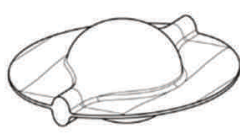

v5

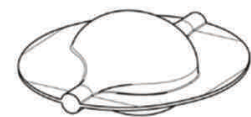

v8

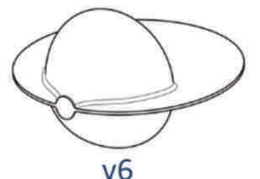

Fig. 2 Geometry versions of the combustion chamber

They intend to change the rotation axis of initially cylinder axial swirl. Geometry v6 is designed for only one injector. Table 1 shows engine parameters. Study [2] presents similar engine with swirl ratio analysis.

Table 1. Engine parameters

\begin{tabular}{|l|c|}
\hline Bore & $65.5 \mathrm{~mm}$ \\
\hline Stroke & $76.4 \mathrm{~mm}$ \\
\hline Displacement volume & $514607 \mathrm{~mm}^{3}$ \\
\hline TDC comb. cha. volume & $21850 \mathrm{~mm}^{3}$ \\
\hline Compression ratio & 24.5 \\
\hline Connecting rod & $125 \mathrm{~mm}$ \\
\hline Crankshafts axis distance & $325.1 \mathrm{~mm}$ \\
\hline Crank angle shift & $24^{\circ} \mathrm{CA}$ \\
\hline Crankshaft rotational speed & $4000 \mathrm{~min}-1$ \\
\hline
\end{tabular}

The simulation starts at angle $610^{\circ} \mathrm{CA}$ and ends at $800^{\circ}$ CA. The initial parameters presented in Table 2 are set for angle $610^{\circ} \mathrm{CA}$.

Table 2. Simulation parameters and initial conditions

\begin{tabular}{|l|c|}
\hline Parameter & Value \\
\hline Simulation range & $610-800^{\circ} \mathrm{CA}\left(720^{\circ}=\mathrm{TDC}\right)$ \\
\hline Pressure & $194634 \mathrm{~Pa}$ \\
\hline Temperature & $428 \mathrm{~K}$ \\
\hline Turbulent kinetic energy & $30 \mathrm{~m}^{2} / \mathrm{s}^{2}$ \\
\hline Turbulence length scale & $0.0013 \mathrm{~m}$ \\
\hline Turbulent dissipation rate & $20769.2 \mathrm{~m}^{2} / \mathrm{s}^{3}$ \\
\hline Laminar flame speed & Maghalchi \& Keck \\
\hline EGR composition & 0.63 \\
\hline Lower heating value & $33,400 \mathrm{MJ} / \mathrm{kg}$ \\
\hline $\begin{array}{l}\text { Cylinder temperature boundary } \\
\text { condtition }\end{array}$ & $373 \mathrm{~K}$ \\
\hline $\begin{array}{l}\text { Piston temperature boundary } \\
\text { condtition }\end{array}$ & $443 \mathrm{~K}$ \\
\hline Heat transfer wall model & Standard wall function \\
\hline
\end{tabular}

\section{Results}

The increase of axial swirl rotational speed tends to higher redirection of the fuel stream from its axial hole direction due to higher local tangential velocities. Also, higher turbulence provides better atomization of the fuel droplets and higher combustion flame front area. This leads to faster combustion and higher thermodynamic efficiency. On the other hand, if the swirl ratio is too negative effects can occur. Increasing high swirl increases the pumping loses. The hot post combustion gases can be scattered throughout the colder combustion regions, intensifying the heat transfer to the combustion chamber walls. During the combustion and gas expansion phase the increased heat transfer leads to decreased thermodynamic cycle efficiency. The heat addiction process is not as isochoric and the gas expansion process is not as adiabatic. Additionally, high swirl ratio means higher local gas velocity close to the chamber walls. This increase the heat transfer coefficient what also increase the heat transfer. Similar conclusions were drawn studies $[3,4]$.

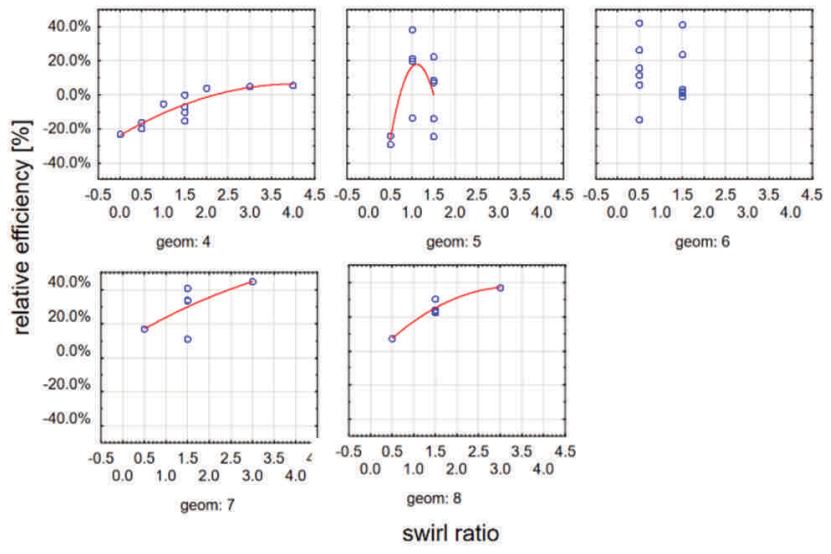

Fig. 3. Relative efficiency and swirl ratio for different geometries

Around 60 cases were calculated for different combustion chambers and injection parameters. Some trends can be distinguished when we compare the results. Figure 3 presents how relative efficiency changes with the change of swirl ratio. All Geometries show similar trend, where increasing swirl ratio increases the relative efficiency up to certain maximum point and any further increase decreases the efficiency. This happens because after certain point the increased convective heat transfer has bigger impact than increase of turbulent flame speed and reaction rate.The heat loses seem to follow a linear trend with the increase of swirl ratio. This is because the heat transfer coefficent is fairly proportional to the increase of tangenal near wall velocity. All geometries follow a steady linear trend of relative heat loss vs. swir ratio.

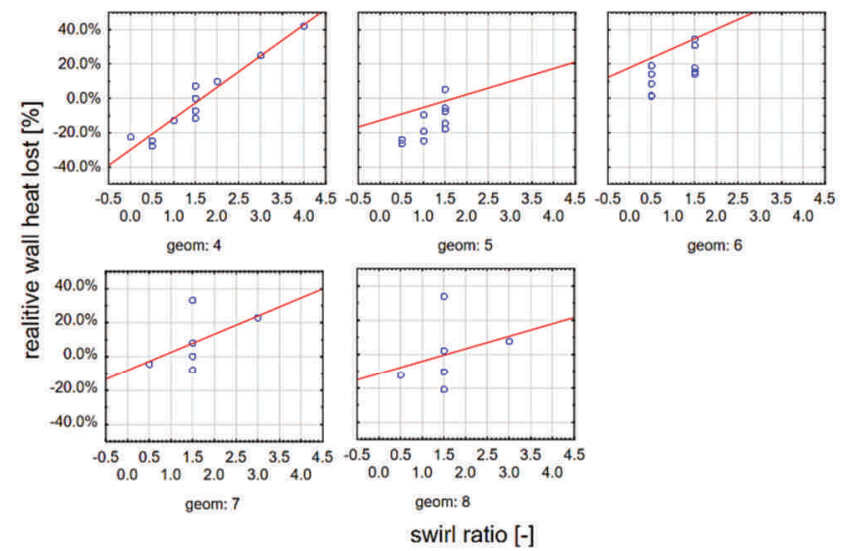

Fig. 4. Relative efficiency and swirl ratio for different geometries 
Figure 5 presents simulation results for geometry v4. Swirl ratio $=0$ result in poor flame surface propagation, low flame velocity and poor injection atomisation. Two injection streams meat at the middle of combustion chamber and expand uniformly in all directions. Increasing the swirl ratio causes the injection streams to deflect from their axial direction. This causes an increased flame front surface and faster combustion.

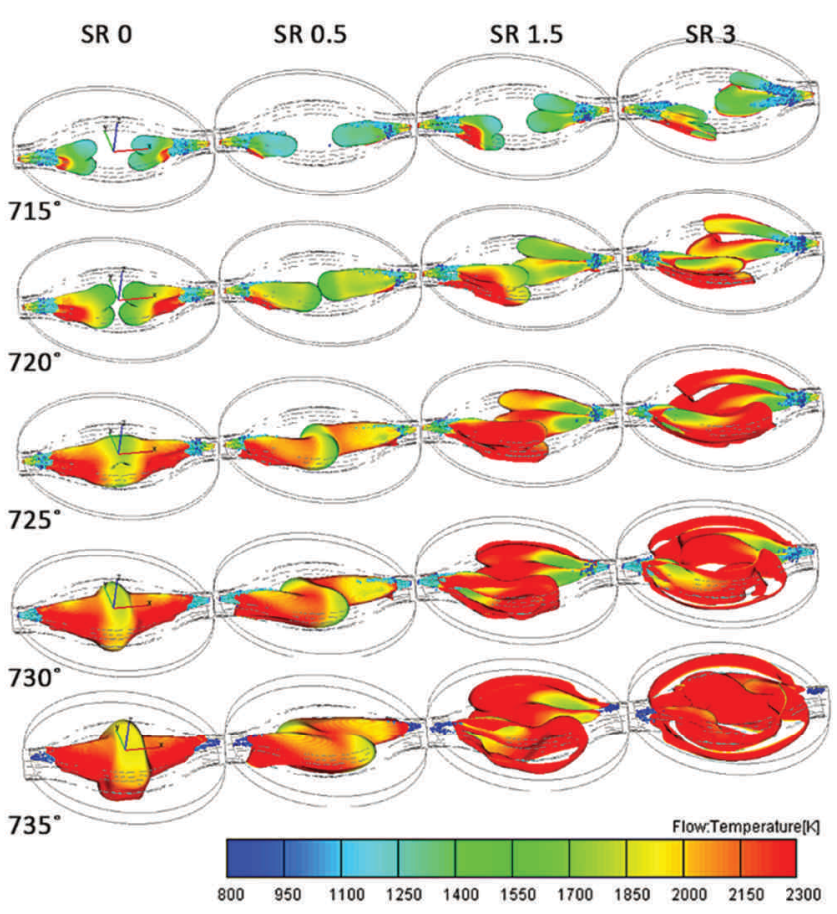

Fig. 5. Injection and combustion visualisation for 4 different swirl ratios and different crank angle potions

Increasing the swirl ratio higher cause the hot gases to flow between the in-between pistons gaps increasing heat loses to pistons and cylinder walls. Therefore, it is important to choose the optimal swirl ratio for a given case. Another study of an opposed piston dual injection engine also shows that there is an optimal swirl ratio for maximum IMEP [5].

Figure 6 shows that increasing the swirl ratio leads to faster combustion process and to higher maximum rate of heat release. This is the biggest factor for the thermal efficiency increase. The values of heat release are high compared to study [6] where lower compression ratio engine is investigated but the trend of swirl ratio impact is similar.

\section{Piston heat load}

In order to analyse the heat load in comparative way the heat flux was recorded (Fig. 7). It is clearly visible that the increase of swirl ratio increase the heat transfer rate throughout the whole cycle. The heat rate peaks near the end of the injection process when nearly all fuel is burned and hot gases come close to combustion chamber walls.

The time integration of heat flux gives the total cumulative energy transferred via convection through the chamber walls (Fig. 8). The increase of swirl ratio increases the total chamber walls heat transfer as the gas temperature and heat transfer coefficient increase. Most heat is transferred through the piston walls, as they compose most surface area of the combustion chamber during the combustion phase. There is no cylinder head so instead most heat is loaded on the pistons. This is the main reason why it is essential to predict convective heat transfer loads in the design process of the engine.

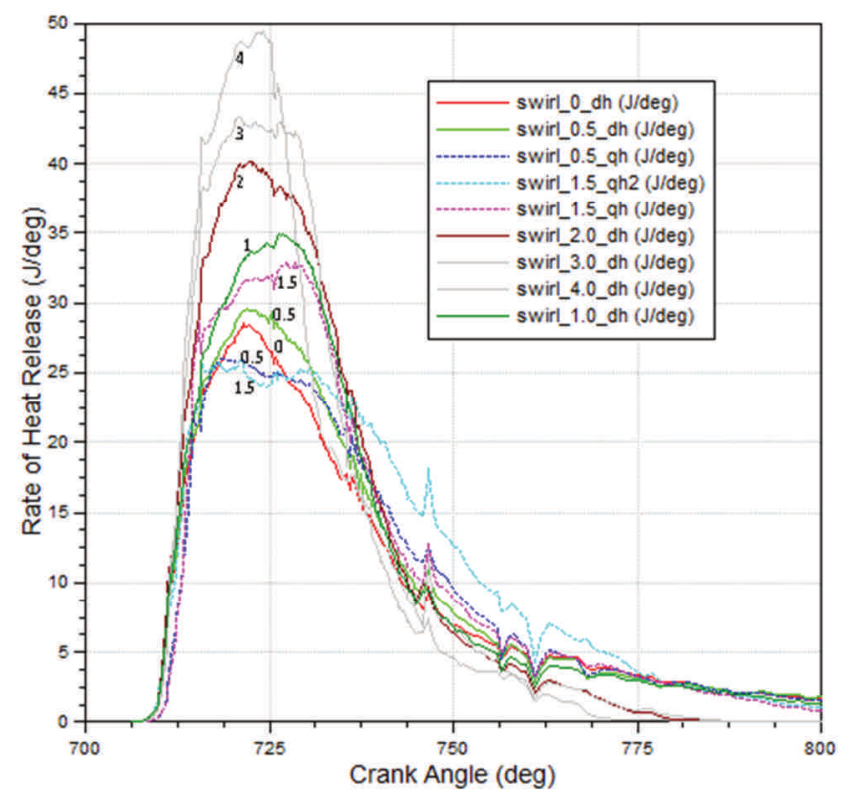

Fig. 6. Rate of heat release in respect to the crank angle for different swirl ratios

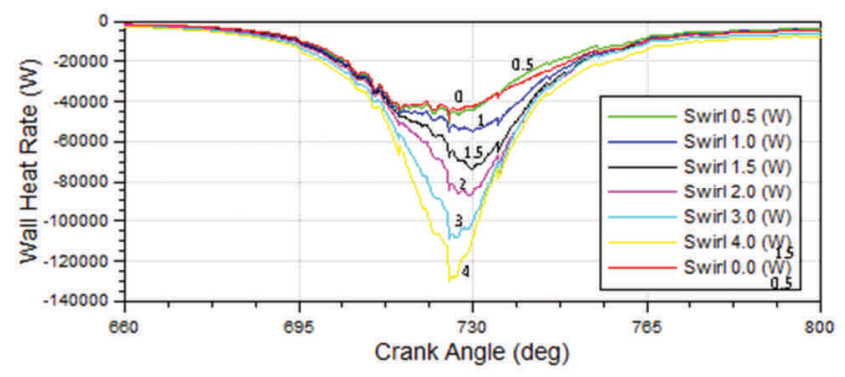

Fig. 7. Heat rate through combustion chamber walls at different crank ankle positions

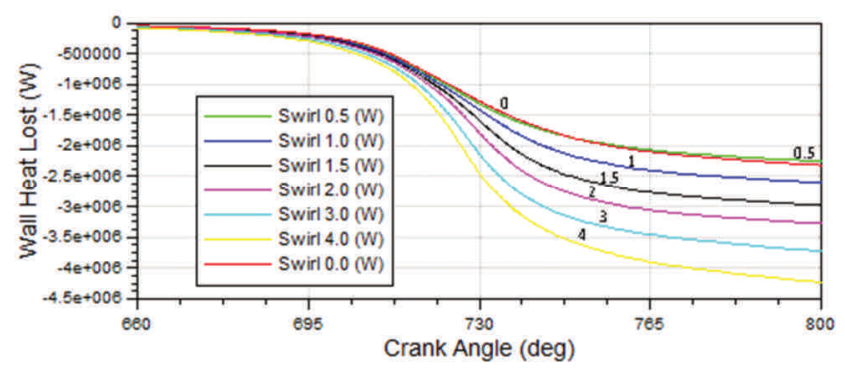

Fig. 8. Cumulative heat transferred through combustion chamber walls at different crank angle positions

The results show that the heat flux can vary vastly with the change of swirl ratio, injection parameters and combustion chamber geometry. It is very important not to exceed the temperature limits if the piston materials. The temperature affects piston strength limits and its thermal expansion. 
Also, if the temperature is too high the oil density and its lubrication abilities decrease. This causes high cylinder wear what decreases engines service life.

\section{Emmision}

The ECFM-3Z+ combustion model allows detailed post flame chemistry, especially the NOx emission. Figure 9 presents the NO mass fraction against the crank angle for different swirl ratios. The increase of swirl ratio leads to more turbulent therefore faster combustion further increasing the in-cylinder peak gas temperature. Therefore, the increase in swirl ratio tend to increase the NO emission. Following studies show similar trend $[7,8]$.

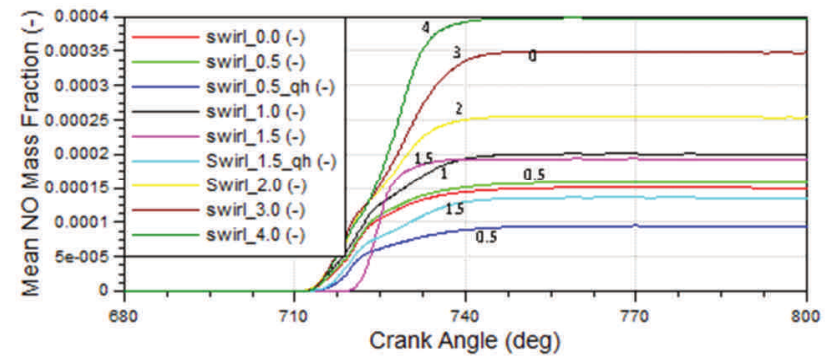

Fig. 9. Mean NO mass fraction at different crank angle positions and different swirl ratios

Soot deposes in the regions of rich mixture in certain temperatures. Because in CI engines diffusion flame is dominant, soot forms in the local rich regions. Due to the high temperature and lean conditions soot a vast amount of soot burn long after the injection process (Fig. 10).

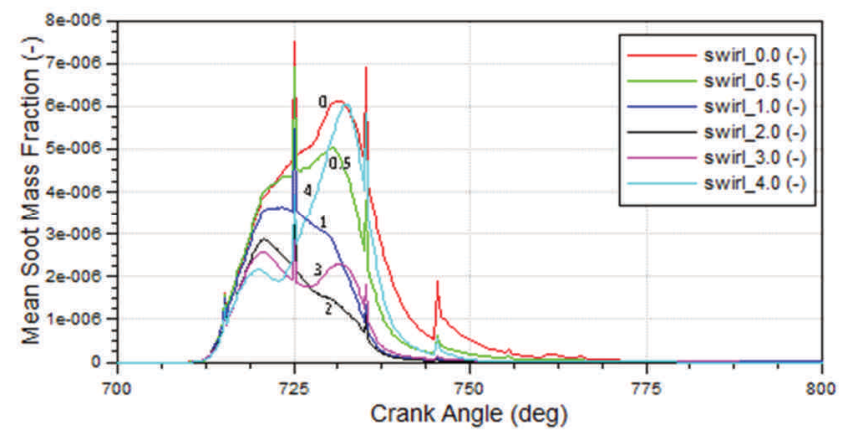

Fig. 10. Mean soot mass fraction in respect to the crank angle for different swirl ratios

Increasing the swirl ratio decreases the amount of soot formed, because better mixture turbulization increases the chance of succesfull post flame combustion. The soot levels are high for all cases when we compare it to european automotive standards.

Study [9] shows an opposite trend for a different engine, because the injection fuel has much higher contact with combustion chamber bowl walls. The main idea of chamber being designed is to limit this contact as much as possible. Figure 11 shows that with the increase in swirl the CO emission decreases both for a maximum value and final value after combustion and expansion process. Increasing swirl ratio has negative effect on $\mathrm{NO}$ emission and positive effect on soot and CO formation. Similar considerations can be found in $[10,11]$.

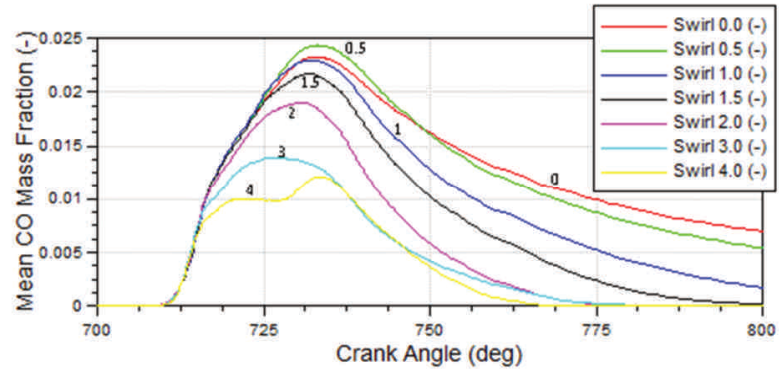

Fig. 11. Mean CO mass fraction against crank angle position for different swirl ratios

\section{Discussion}

The distance between the injection stream and chamber walls has a big impact on combustion process. If the fuel meets cold chamber wall before it evaporates it may not be combusted leading to incomplete combustion. This has negative effect on exhaust emission and indicated power. Even during combustion when the flame front meets cold chamber walls the heat efficiency drops dramatically, as the heat is inevitably lost via cooling. The shape of combustion chamber also induces swirl, tumble and squish. The swirling flow has a big influence on fuel stream trajectory, fuel atomisation and evaporation and combustion process itself including the turbulent flame speed. Piston induced squish forces the mixture into small spherical piston bowl. Decreased gas inertia increases the swirl rotational velocity. After heat addition with increased temperature the gas kinematic viscosity increases too. This makes the swirl dissipate faster and further decrease its rotational velocity through the gas expansion process. Higher swirl makes the injection fuel stream deflect more (fig. 5). The fuel droplet atomisation is better and the flame surface area increases. The larger the flame surface area the faster the combustion process, making the thermal efficiency higher. If the swirl ratio is too high the efficiency decreases. As the heat loses to the walls linearly increase with the swirl ratio, the combustion speed increases with decreasing gradient until its maximum. Also, high swirl ratio tends to force the hot gases to the gap between the pistons, decreasing the heat that is transformed into pressure. When we increase the swirl ratio the combustion process is faster and makes the heat addition process more isochoric and the overall heat efficiency is higher. The increased heat transfer coefficient negatively impacts the engine conditions. Increased heat transfer increases the heat load on the pistons. In such engine, it is important to maintain piston temperature below its limits. High Hotspots can occur in some locations, intensifying soot and hydrocarbons emission. To sum up:

- for simulated cases swirl ratio between 1 and 1.5 gives best efficiency with acceptable amount of heat load to the pistons,

- increasing swirl ratio has negative effect on NO emission and positive effect on soot and CO formation,

- for the perpendicular to cylinder axis injectors orientation the swirl ratio has a big influence on the injection trajectory.

\section{Acknowledgments}

Prepared in collaboration with WSK PZL-Kalisz S.A design office. 


\section{Nomenclature}

CI compression ignition

DI direct injection

CA crank angle

EGR exhaust gas recirculation
SI spark ignition

TDC tom dead center

IMEP -indicated mean effective pressure.

\section{Bibliography}

[1] PERIN, F., MILES, P.C., REITZ, R.D. A comprehensive modeling study of in-cylinder fluid flows in a high-swirl, light-duty optical diesel engine. Computers \& Fluids. 2014, 105, 113-124.

[2] MA, F., ZHAO, C., ZHANG, F. et al. Effects of scavenging system configuration on in-cylinder air flow organization of an opposed-piston two-stroke engine. Energies. 2015, 8, 5866-5884.

[3] OLMEDA, P., MARTIN, J., GARCIA, A. et al. A combination of swirl ratio and injection strategy to increase engine efficiency. SAE Technical Paper. 2017, 10(3).

[4] KOCSIS, M.C., JOO, S., BRIGGS, T., ALGER, T. Impact of swirl ratio on combustion performance of a non-pent roof combustion chamber engine. SAE Technical Paper. 2015.

[5] ZHANG, Z., ZHAO, C., XIE, Z. et al. Study on the effect of the nozzle diameter and swirl ratio on the combustion process for an opposed-piston two-stroke diesel engine. Energy Procedia. 2014, 542-546.

[6] PERINI, F., DEMPSEY, A., REITZ, R.D. et al. A computational investigation of the effects of swirl ratio and injection pressure on mixture preparation and wall heat transfer in a light-duty diesel engine. SAE Technical Paper. 2013.
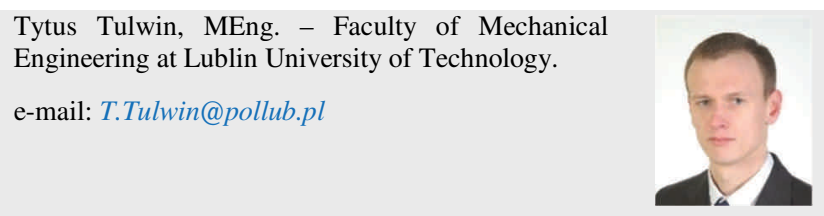

Zbigniew Czyż, MEng. - Faculty of Mechanical Engineering at Lublin University of Technology.

e-mail: Z.Czyz@pollub.pl
[7] GAFOOR, A., GUPTA, R. Numerical investigation of piston bowl geometry and swirl ratio on emission from diesel engines. Energy Conversion and Management. 2015, 101, 541-551.

[8] KOOK, S., KOOK, S., MILES, P.C. et al. The effect of swirl ratio and fuel injection parameters on $\mathrm{CO}$ emission and fuel conversion efficiency for high-dilution, lowtemperature combustion in an automotive diesel engine. SAE Technical Paper. 2006, 2006-01-0197.

[9] WEI, S., JI, K., LENG, X. et al. Numerical analysis on the effect of swirl ratios on swirl chamber combustion system of DI diesel engines. Energy Conversion and Management. 2013, 75, 184-190.

[10] SU, L., LI, X., HE, X. LIU, F. Experimental research on the diffusion flame formation and combustion performance of forced swirl combustion system for DI diesel engines. Energy Conversion and Management. 2015, 106, 826-834.

[11] LIA, X., ZHOUA, H., SUB, L. et al. Combustion and emission characteristics of a lateral swirl combustion system for DI diesel engines under low excess air ratio conditions. Fuel. 2016, 184, 672-680.

Prof. Mirosław Wendeker, DSc., DEng. - Faculty of Mechanical Engineering at Lublin University of Technology.

e-mail: M.Wendeker@pollub.pl 